\title{
WAGES AND WORKING TIME IN THE 'GIG ECONOMY’
}

\author{
A.C.L. Davies*
}

Since the gig economy began to form part of the public consciousness, many labour lawyers have been preoccupied with one central question: are people working in the gig economy employees, or more likely workers, in English law? Securing one of these statuses is, of course, crucial to gaining access to all, or at least some, statutory employment rights. Determining the employment status of people working in the gig economy is a complex matter, for at least two reasons. First, although the gig economy is a convenient shorthand, it is not a technical term and a great variety of employment types and working practices are contained within it. Second, even in the case of a particular platform, the precise arrangements for the provision of work and pay may vary over time in ways that might affect the courts' categorisation of the situation in law. Although the courts are now better attuned to the need to examine the reality of the situation and not just the written terms and conditions, cases often turn on quite fine distinctions. ${ }^{1}$

While much important work has been done - and must continue to be done - on these questions, I want to draw attention to a different but related set of issues. Assuming that it is possible to show that at least some individuals in the gig economy have worker status in law, what issues will arise when those individuals try to invoke the various worker rights to which they will be entitled? My focus in this short contribution will be on existing rights under the National Minimum Wage Act 1998 and the Working Time Regulations 1998 (WTR). ${ }^{2}$ As I explain below, these rights present particular problems of application because they are not particularly well-designed for workers whose work consists of a series of tasks. There is, of course, a much broader debate to be had about the specific needs of gig economy workers for protection and the potential inadequacies of existing rights in providing that protection, but again this is widely discussed elsewhere and is beyond the scope of the present contribution.

I recognise that there is a risk inherent in my approach: identifying the difficulties that workers might face in invoking their rights could be used as a reason for denying them the rights in the first place. This type of circular reasoning is all too common in employment settings.

Nonetheless, I think it is important to acknowledge that arduous test cases establishing worker status are unlikely to be the end of the story, and to start considering the next steps.

\section{Scope and definitions}

Although it is difficult to generalise about the gig economy, a key characteristic of the vast majority of work in this setting is the payment mechanism: working people are paid for each task they perform. This is one of the core ideas captured by the 'gig' label. ${ }^{3}$

Being paid by the task is, of course, nothing new. Employers have long used piece rates to motivate workers doing monotonous tasks, or paid salespeople on a commission basis. But it is clear that technology facilitates this approach. For example, apps can be used to log the

\footnotetext{
* Professor of Law and Public Policy, Faculty of Law, University of Oxford. I consider developments up to 3 March 2020. I am grateful to Alan Bogg for comments on a draft. Responsibility for errors and omissions remains my own. 1 Autoclenz Ltd v Belcher [2011] UKSC 41, [2011] ICR 1157.

2 Working Time Regulations 1998 (SI 1998/1833), as amended, implementing the Working Time Directive 2003

(WTD) (Directive 2003/88/EC).

3 See, generally, J Prassl, Humans as a Service (OUP 2018).
} 
completion of each task and to calculate and distribute payment in a way that would have been highly labour-intensive to do manually. It seems likely that this technology will spill over into more 'traditional' employment over time as employers perceive the benefits (to them) of being able to monitor workers' activities more closely and pay them only for work performed. For example, the use of apps to assign 'jobs' to workers is already common in the home care sector, where there is a widespread problem of non-compliance with the clear obligation to pay the National Minimum Wage (NMW) for travel time between visits. ${ }^{4}$

Being paid by the task is not, in itself, a particularly helpful indicator of a person's employment status. Although genuinely self-employed people are usually paid in this way, it does not follow that everyone paid by the task is running their own business. The employer may have introduced a task-based payment mechanism into a relationship that otherwise has all the hallmarks of 'employee' or 'worker' status in order to promote productivity, as the piece-rate example shows. ${ }^{5}$ Some jeopardy around payment is not the same as business risk, ${ }^{6}$ though sometimes the courts have found it hard to capture this distinction in practice. ${ }^{7}$

A much more significant factor is how the price for the task is determined. For example, a genuinely self-employed person running their own business would be expected to set the price themselves, or at least negotiate at arm's length with the customer. But where the price is determined by the platform, it may be possible to establish worker status. This was found to be the case by the majority in the Court of Appeal in Uber. ${ }^{8}$ It was clear that, although the platform in that case generated an invoice from the driver to the customer for payment, the driver played no role in collecting the payment or, most importantly, deciding how much it would be, since this was set by the platform. This was one of many indications that the drivers could properly be classified as 'workers' in law. At the time of writing, this decision is on appeal to the Supreme Court.

Achieving 'worker' status entitles the individual to the NMW and to various rights under the WTR, including rest breaks, rest periods and paid annual leave. Not surprisingly, these rights have been drafted taking traditional employment relationships as their starting-point. It is easy to apply the NMW to someone whose pay is expressed as a rate per hour, and to calculate rest breaks and paid holidays for someone who works 9am-5pm, Monday to Friday. Some effort has been made to take account of other types of work. For example, there are methods of checking whether workers who are paid piece rates are receiving the NMW, and the entitlement to paid annual leave is expressed in terms of 'weeks' to accommodate different working patterns. But it is not clear that these strategies are sufficient for workers paid by the task in the gig economy and other contexts.

\section{National Minimum Wage Act 1998}

I turn first to the NMW entitlement of workers who are paid by the task. The Regulations offer four possible bases for calculating NMW entitlement: time work, salaried work, output work and unmeasured work. ${ }^{9}$ Depending on the circumstances, a worker paid by the task could be considered under at least three of these categories, with varying consequences. Even the simplest

\footnotetext{
${ }^{4}$ Her Majesty's Revenue and Customs (HMRC), National Minimum Wage: Compliance in the Social Care Sector (2013).

${ }^{5}$ For example, Nethermere (St Neots) Ltd v Gardiner [1984] ICR 612 (CA).

${ }^{6}$ Market Investigations Ltd v Minister of Social Security [1969] 2 QB 173.

7 See, for example, Quashie v Stringfellow Restaurants Ltd [2012] EWCA Civ 1735, [2013] IRLR 99.

${ }^{8}$ Uber BV v Aslam [2018] EWCA Civ 2748, [2019] ICR 845.

${ }_{9}$ National Minimum Wage Regulations 2015 (SI 2015/621), r. 30, r. 21, r. 36, r. 44.
} 
method of ensuring that the NMW is paid - looking retrospectively at the hours actually worked - is not easy to apply to task-based work.

It may seem odd to begin by considering 'time work' as a possibility for a worker paid by the task. However, there is evidence that some platforms operate on the basis of allocating shifts to workers, even though the intention is only to pay them for tasks undertaken during the shifts. ${ }^{10}$ The benefit of this system for the platform is having the reassurance that a certain number of workers will be available at any given time to fulfil customer demand. This can be an advantage in sectors such as food delivery where prompt responses to customer orders are crucial.

Platforms can use the system of allocating shifts to reward workers who are particularly loyal or who have good customer ratings, by giving them first pick of the available shifts over workers who work less frequently for the platform or whose ratings are poorer, and of course there are likely to be consequences for any worker who logs off without completing the agreed shift. In this fact scenario, it is arguable that the worker is engaged in 'time work' because they must be at the employer's disposal for the agreed period of time. Where this is so, NMW entitlement is based on the number of hours for which the worker is required to be working or 'available for work'. ${ }^{11}$ Of course, this does not preclude the employer from continuing to pay the worker for each task performed, but care would need to be taken to ensure that this form of payment met the employer's NMW obligations, particularly on a quiet shift. A key characteristic of paying workers by the task is that the risk of low demand falls on the worker, but if the arrangements can be construed as time work, some of that risk moves back to the employer.

Another way of thinking about work paid by the task is as 'output work'. This applies where the employer calculates payment by reference to the number of pieces produced by the worker regardless of the time taken to produce them. ${ }^{12}$ The worker must be paid the NMW either by reference to hours actually worked (an issue I return to below), or by reference to a 'fair' piece rate calculated using the rated output mechanism set out in the legislation. This is designed to ensure that the employer is likely to be paying the NMW even to workers who are somewhat below average in terms of the speed with which they complete each piece. The rated output approach could work well for some types of gig economy work, such as routine data entry paid by the item. However, there is a long-standing concern that it may be difficult for enforcement agencies or tribunals to challenge or check employers' calculations given that all the relevant data and expertise is likely to be in employers' hands. Although we typically think of output work in terms of piece rates, it worth noting that it is also applicable to workers paid varying amounts according to the value of the work they complete, such as sales staff paid on a commission basis, making it an option for a wider range of gig economy platforms. The more complex the situation, the harder it will be to judge the fairness of the employer's payment arrangements.

Alternatively, work paid by the task could be treated as 'unmeasured'. ${ }^{13}$ This is the default category for work that does not fall into the other three categories. HMRC guidance indicates that this is likely to be the correct route for individuals who are only required to work when work is available,$^{14}$ and indeed an earlier version of the legislation expressly offered this as an example. ${ }^{15}$ Thus, it seems to be the most likely approach to most task-paid work in the gig

\footnotetext{
${ }^{10}$ See M Ivanova et al, Foodora and Deliveroo: the App as a Boss? (Hans Böckler Stiftung 2018).

11 Above n 9, r. 30.

12 Ibid r. 36.

13 Ibid r. 44.

${ }^{14}$ HMRC, National Minimum Wage Manual (2016), NMWM07110.

15 National Minimum Wage Regulations 1999 (SI 1999/584), r. 6.
} 
economy. Again, if this is the correct classification, the employer has two options for paying the minimum wage: payment by reference to hours actually worked (discussed further below), or payment on the basis of a 'daily average agreement'.

The 'daily average agreement' is a written agreement that the employer must provide to the worker in advance setting out the number of hours they are expected to work each day. This estimate must be 'reasonable', though (as in the case of the rated output calculation) it can be difficult for enforcement agencies or tribunals to assess this. Controversially, the 'daily average agreement' need not correspond to the amount of time for which the worker must be available to the employer. Thus, it is perfectly permissible for the worker's contract to require them to be present at the workplace and available for work for, say, 12 hours, but the 'daily average agreement' to specify payment for, say, six hours. These agreements are common in the care sector where workers are required to spend the day or night in the home of a vulnerable person but may not be continually engaged in work tasks. ${ }^{16}$ This gives rise to the highly problematic result that workers are required to be at the employer's disposal for long hours for which they do not receive any payment. ${ }^{17}$ It is also difficult, if not impossible, to come up with a clear logical distinction between cases treated as 'time work' (where 'available time' must be paid at the NMW rate) and 'unmeasured work', where the 'daily average agreement' can be used. In the gig economy context, the 'daily average agreement' might provide a route for platforms to comply with the NMW without fundamentally changing their business model. Workers could be paid by the task, but available on the platform for much longer waiting for work, and the employer could comply with the NMW by specifying an expected number of hours of work and topping up the worker's pay to that level on quieter days.

Under both the output and unmeasured approaches, the alternative to making complex calculations is simply to ensure that the worker is paid the NMW for hours actually worked. It might be thought that this would have particular appeal for gig economy employers because in many cases they will already have access to information about hours worked via their apps and could easily build in a mechanism for checking that workers are receiving the NMW. But what counts as an 'hour worked' for these purposes? This issue has already arisen in the Uber litigation. ${ }^{18}$ The argument on behalf of the drivers is that (if worker status can be established) they are 'working' when they are logged in to the app and waiting in their vehicle in the relevant area, ready to accept work. The alternative view advanced by Uber is that they are working only when they are carrying a passenger. What the Court of Appeal described as a 'middle course' would expand this slightly to include the time between accepting the assignment and collecting the passenger as well as the time spent taking the passenger to the destination. ${ }^{19}$ The majority in the Court of Appeal was content to uphold the tribunal's conclusion that the drivers were working when they were logged into the app. The tribunal had found that 'being available is an essential part of the service which the driver renders' because of the need to have an oversupply of drivers in order to meet customer demand. ${ }^{20}$ Underhill LJ, dissenting, preferred the view that drivers were working from the time they accepted a trip because they were under no obligation to accept trips and were free to offer their services on other similar apps while they were waiting

\footnotetext{
${ }^{16}$ See, for example, Walton v Independent Living Organisation Ltd [2003] EWCA Civ 199, [2003] ICR 688.

17 See, generally, ACL Davies, 'Getting More than you Bargained for? Rethinking the Meaning of "Work" in

Employment Law' (2017) 46 ILJ 477.

18 Above n 8, [99]-[104].

${ }^{19}$ Ibid [100].

${ }^{20}$ Quoted in ibid [101].
} 
(though there was no clear evidence that this occurred in practice) ${ }^{21}$ Clearly a concern about the tribunal's approach was that if drivers spent long periods of time logged in, their earnings might average out below the NMW. However, Uber already logs drivers out if they turn down too many requests, so it is clear that it has means of defending itself against drivers trying to 'inflate' their working time. No doubt other mechanisms could also be devised, such as limiting the number of workers who can log on at quiet times, or logging workers out if there is no work available after a certain period of time.

Trying to pay workers only for core work tasks and not for other activities such as waiting, preparing or clearing up is all too common, even in traditional employment settings. But it is a central feature of the gig economy, facilitated by technology which can draw tiny distinctions between different elements of a worker's activities. It is by no means impossible to apply the NMW in the context of a gig economy job in which the worker is paid per task performed, but at least two problems arise. One is that, by providing escape routes such as the 'daily average agreement', the Act makes it possible to maintain employment arrangements in which workers are available for long periods of time but paid only for core work tasks. It would have been preferable to have structured the legislation around a much stronger presumption that time spent at the employer's disposal should give rise to NMW entitlement. The other problem is the uncertainty inherent in the understanding of 'work' itself, which is also open to exploitation by employers. It is to be hoped that the courts adopt a worker-protective interpretation of this term. Of course, there are broader issues too - NMW entitlement may not help very much if the worker is responsible for providing expensive equipment to carry out the work, such as taxi drivers providing their own cars - but these are beyond the scope of the present contribution.

\section{Working Time Regulations 1998}

Complexities also arise in attempting to apply the various rights afforded to 'workers' by the W'TR 1998, designed primarily for people who work for agreed periods of time, to gig economy workers whose work is presented as a series of tasks.

The Regulations entitle a worker to 5.6 weeks' annual leave per year, subject to a 28 -day cap. ${ }^{22}$ This must be paid at a rate corresponding to the worker's 'normal remuneration'. In relation to workers whose work is task-based, two problems present themselves: calculating their leave entitlement, and calculating their 'normal remuneration'.

By expressing the leave entitlement in terms of weeks, the Regulations are intended to accommodate a variety of different patterns of work. For example, someone who works two days per week is still entitled to 5.6 weeks' annual leave per year, but the 'value' of this in terms of paid days off is lower than it would be for a full-time worker. This approach could function reasonably well for task-paid workers if they have a regular working pattern, such as working every weekend on a particular platform.

Problems arise where the task-based work is irregular and has no obvious weekly pattern. Government guidance labels this 'intermittent' work and indicates that the employer must ensure that intermittent workers have 5.6 weeks' annual leave per year, but does not offer any further advice on how this should be done. ${ }^{23}$ This might be taken to suggest that the employer can

${ }^{21} \operatorname{Ibid}[156]-[163]$.

22 WTR 1998, rr. 13, 13A and 16.

${ }^{23}$ See Department for Business, Energy and Industrial Strategy (BEIS), How to Calculate Holiday Entitlement for

Workers on Different Types of Contract (November 2019), available at 
simply calculate the number of days not worked in any given year, and provided that it amounts to at least 5.6 weeks it has (retrospectively) complied with the Regulations. However, this retrospective approach would clearly be incompatible with the Regulations, for two reasons. First, it would not fit with the requirement (on either the employer or the worker) to give notice in advance that time is to be taken as leave laid down by r. 15. While this still means that a wellorganised employer can determine when workers take their leave, it does at least ensure that workers get some notice of days on which they will not be expected to work and can plan accordingly. Second, the case-law suggests, rightly, that time spent waiting to be called upon to work is unlikely to count as leave. 'Working time' is defined in r. 2 as 'any period during which [the worker] is working, at his employer's disposal and carrying out his activity or duties'. In a series of cases in the context of 'on call' time, the Court of Justice has held that a worker is working if they are required to be at the employer's premises and available for work, even if they are provided with a place to sleep when there are no work tasks to be done. ${ }^{24}$ This may also be true of time spent waiting at home if the worker's freedoms are significantly constrained. ${ }^{25}$

An important feature of the right to annual leave is that the time spent on leave must be paid at the rate of the worker's 'normal remuneration'. This is key to enabling workers to take leave in practice. But it is also challenging in the case of workers paid by the task whose remuneration can vary dramatically from week to week. At present, where a worker has no normal working hours, their 'normal remuneration' must be calculated by reference to their average earnings over a 12 -week reference period prior to the proposed holiday date. ${ }^{26}$ Importantly, the 12 -week period is the previous 12 weeks in which the worker received payment, so any weeks with no earnings at all are excluded and must be replaced with 'older' weeks in which money was earned.

Nevertheless, the 12-week period can produce quirky results, and from April 2020 it will be extended to 52 weeks, ${ }^{27}$ in response to a recommendation in the Taylor Review. ${ }^{28}$

It is perhaps worth noting that, for task-paid and other intermittent workers, some employers traditionally refused to provide payment when leave was taken but claimed instead that a sum in respect of holiday pay was 'rolled up' into the workers' hourly rate of pay. This practice was found to be in breach of the Working Time Directive in the Robinson-Steele case because of the likelihood that not receiving pay at the time of taking leave would discourage workers from using their leave entitlement. ${ }^{29} \mathrm{~A}$ more pragmatic approach might be to say that workers who are doing low-paid 'on demand' work are unlikely to take holiday anyway and would prefer the extra money, but there would still be a significant problem of determining whether that money was indeed 'extra'. One of the more bizarre elements of the Taylor Review was a recommendation to introduce 'rolled-up' holiday pay but this was rejected by the government because of the need to give effect to the ruling in Robinson-Steele. ${ }^{30}$

https://www.gov.uk/government/publications/calculating-holiday-entitlement-for-workers/how-to-calculateholiday-entitlement-for-workers-on-different-types-of-contract (last visited 3 March 2020).

${ }^{24}$ Case C-303/98 Sindicato de Médicos de Asistencia Pública (SIMAP) v Consellería de Sanidad EU:C:2000:528, [2000] ECR

I-7963; Case C-151/02 Landeshauptstadt Kiel v Jaeger EU:C:2003:437, [2003] ECR I-8389.

${ }_{25}$ Case C-518/15 Ville de Nivelles v Matrak EU:C:2018:82, [2018] ICR 869.

${ }^{26}$ WTR 1998, r. 16, applying ss. 221-224 Employment Rights Act 1996.

27 Employment Rights (Employment Particulars and Paid Annual Leave) (Amendment) Regulations 2018 (SI 2018/1378)

28 Matthew Taylor, Good Work: the Taylor Review of Modern Working Practices (July 2017).

${ }^{29}$ Case C-131/04 Robinson-Steele v RD Retail Services Ltd EU:C:2006:177, [2006] ECR I-2531.

30 Above n 28, 47; and see BEIS, Government Response to the Taylor Review of Modern Working Practices (February 2018), 34. 
Space precludes a discussion of the full range of rights in the W'TR, but it is instructive to consider one other example. Under r. 12(1), the worker is entitled to a 'rest break' where their 'working time is more than six hours'. The details of this may be set by collective or workforce agreement in accordance with r. 12(2), but the default is a break of at least 20 minutes which the worker is entitled to spend away from their workstation (if applicable). Since this break is unpaid, it is unlikely in practice that many workers doing intermittent, task-based work would seek to enforce it, but it raises interesting analytical issues.

One issue is whether task-based workers are entitled to this right at all. The W'TR contain a variety of exclusions, including one for 'unmeasured work'. ${ }^{31}$ Workers with this type of work are not entitled to rest breaks (or to daily or weekly rest periods, or the 48-hour maximum limit on the working week). Regulation 20(1) defines unmeasured work as taking place where 'on account of the specific characteristics of the activity in which [the worker] is engaged, the duration of his working time is not measured or predetermined or can be determined by the worker himself. This is often presented as the exception for 'managing executives' - an example given in the Directive and Regulations - but there is little guidance on the application of the provision to other types of work. ${ }^{32}$ It is of obvious relevance to workers paid by the task for two reasons: their working time may be determined by the time it takes to complete a task, and they may be free to decide when to make themselves available for work. However, it is important not to jump to the conclusion that all task-paid workers are excluded under r. 20. As we saw above in relation to the NMW, some task-paid workers in fact work recognisable shifts, often after being encouraged to compete for the most lucrative shifts by the employer. But even where that is not the case, there is some hope. Any derogation should be construed narrowly, and with workerprotective objectives in mind, particularly where the rights of precarious workers are at stake. ${ }^{33}$ Moreover, the derogation does not apply to workers whose working time is only 'partially' unmeasured. ${ }^{34}$ This could prove highly significant in cases where the worker is free to start work at a time of their choosing, but not free to stop until the task is completed. This might well be the case for drivers or delivery riders, for example, particularly where they are not told their destination in advance, and thus have no ability to decide whether they want to continue working for the time the task is likely to take. Any attempt by the employer to specify the number of tasks to be completed is likely to preclude application of the r. 20 derogation since this indirectly dictates the worker's working time..$^{35}$

If the r. 12 right to a rest break is applicable at all, a key question in respect of someone who works by completing a series of tasks is how to calculate their 'working time' for the purposes of this provision. We saw above in relation to annual leave that time spent waiting to be called upon to work is more likely to count as working time in this context than it is for NMW purposes, because of the interpretations adopted by the Court of Justice. In the specific context of

\footnotetext{
31 W'TR 1998, r. 20; WTD Article 17.

32 European Commission, Interpretative Communication on Directive 2003/88/EC of the European Parliament and of the Council Concerning Certain Aspects of the Organisation of Working Time (2017/C 165/01), 45.

33 See, for example, Case C-173/99 R (BECTU)) v Secretary of State for Trade and Industry EU:C:2001:356, [2001] ECR I-4881, as an illustration of the Court's worker-protective approach.

34 Above n 32, and see Case C-484/04 Commission of the European Communities v United Kingdom EU:C:2006:526, [2006] ECR I-7471.

35 Compton v St Regis Paper Co Ltd ET Case No.1201178/99, cited in R Hobbs et al, 'Opting Out of the 48-Hour Week: Employer Necessity or Individual Choice?’ (2003) 32 ILJ 223.
} 
interrupted rest breaks, the UK courts have held in a number of cases that time during which the worker is liable to be called on to perform work tasks does not count as a genuine rest break. ${ }^{36}$

In the gig economy context, this would suggest that working time does extend beyond the time spent performing particular work tasks. For example, in driving and food delivery roles, it is possible to signal availability for work by logging into the relevant app and waiting in a particular location. ${ }^{37}$ This time should be treated as working time for WTR purposes as well as time spent conveying passengers or making deliveries. Platforms have ample opportunity to protect themselves against abuse by logging workers out if there is no work available within a reasonable time or if available work is turned down too often. However, there are other contexts in which it is much harder to signal availability for work in this way. For example, an IT worker sitting at home browsing an app looking for work opportunities is, in some sense, available for work, but more in terms of seeking work than being at the 'employer's disposal'. ${ }^{38}$

Even given the relatively generous definition of working time, it remains a problem in the context of some gig economy employment that the employer does not know at the start of the worker's working day for how long they will be working. Guidance suggests that the break must be taken during the working day and cannot legitimately be taken at the beginning or end, though this is not made clear in the Regulations themselves. ${ }^{39}$ In a 'typical' job with an eight-hour day, it is easy to recognise that the worker is entitled to a 20-minute rest break and to encourage them to take it at lunch time, for example. It is much harder where the worker logs in to an app but may log out at any time, with or without reaching the six-hour point at which the rest break entitlement is triggered. Encouraging the worker to take the break after six hours of work seems to be the only practical solution to this, though in some cases it could mean that the worker takes the break at, or close to, the end of the working day. Given platforms' capacity to monitor workers' activities very closely, it should be relatively easy for them to send workers a suitablyworded message. This would provide an important counterweight to messages discouraging workers from logging out when there is ongoing consumer demand.

\section{Conclusion}

None of this should be taken to suggest that there is no point in seeking 'worker' status for working people in the gig economy. Rights not to be discriminated against, either under the Equality Act 2010 or on the basis of trade union membership, are potentially very important consequences of this status. ${ }^{40}$ But, in the absence of statutory reform, there may be some challenges involved in applying the NMW and working time rights to workers whose work is organised and paid by the task. The courts will need to bear in mind the worker-protective aims of these rights when interpreting them, in order to overcome the pernicious effects for workers of the task-based approach.

\footnotetext{
${ }^{36}$ See, for example, MacCartney v Oversley House Management [2006] ICR 510 (EAT).

${ }^{37}$ See Uber, above $\mathrm{n} 8$.

38 See Matzak, above n 25, for circumstances in which a worker on call at home is regarded as 'working'.

39 https:/ / www.gov.uk/rest-breaks-work/taking-breaks (last visited 3 March 2020).

40 Trade Union and Labour Relations (Consolidation) Act 1992, Part III.
} 